\title{
Recurrent phenotypic selection for low grasshopper food preference in rangeland alfalfa
}

\author{
J.D. BERDAHL, G.B. HEWITT, AND R.H. MILLER
}

\section{Abstract}

Grasshopper [Melanoplus spp. and Camnula pellucida (Scudder)] feeding is an important factor that can prevent establishment and reduce yields of alfalfa [Medicago sativa subsp. $X$ varia (Martyn) Arcang.] interseeded into semiarid rangelands of the northern Great Plains. Objectives of this study were to determine narrowsense heritability estimates of grasshopper preference for an alfalfa population and to develop low-preference alfalfa germplasm adapted to rangeland use. The base population was derived from 5 cultivars and an experimental strain, all of $M$. sativa $L$. subsp. sativa $\times M$. sativa subsp. falcata (L.) Arcang. parentage, that had been developed for rangeland use in the northern Great Plains. Except for cycle 4 which was conducted in a greenhouse, each cycle of recurrent phenotypic selection involved transferring replicated half-sib families of 6-to 8-week-old plants in flats to $a$ field site with a heavy infestation of grasshoppers. Half-sib families were scored for defoliation when the entire population was at least $50 \%$ defoliated. Narrow-sense heritability estimates of defoliation under greenhouse conditions for 31 half-sib families and their respective parents ranged from 45 to $58 \%$, depending on how defoliation from the multi-species grasshopper populations was measured. Alfalfa populations produced from cycles 1,3 , and 5 of recurrent phenotypic selection were evaluated simultaneously under greenhouse conditions with a common grasshopper population and rated for defoliation on a scale from 1-5 where $1=0-20 \%$ and $5=$ 81-100\% defoliation. Mean defoliation decreased significantly $(P<0.05)$ from 3.83 to 3.25 from cycle 1 to cycle 3 , but the small decrease from 3.25 to 3.15 from cycle 3 to cycle 5 was not significant. The lack of progress from cycle 3 to cycle 5 was attributed to a major change in species composition of the grasshopper populations used in the selection process.

Key Words: Medicago sativa subsp. $\times$ varia, Melanoplus spp., insect resistance, grasshopper defoliation, heritability

Increased forage yield, forage quality, and livestock gains have resulted from introduction of alfalfa [Medicago sativa subsp. $X$ varia (Martyn) Arcang.] into rangeland in the subhumid and semiarid northern Great Plains region (Lorenz and Rogler 1962, Campbell 1963, Gomm 1964). Several root proliferating cultivars with improved persistence have been developed from $M$. sativa $\mathrm{L}$. subsp. sativa $\times M$. sativa subsp. falcata (L.) Arcang. germplasm for use in rangeland (Rumbaugh et al. 1964, Heinrichs et al. 1979), but successful establishment continues to be a problem. Rumbaugh and Thorn (1965) reported that drought and grasshopper (Orthoptera: Acrididae) feeding in July and August were important factors that prevented establishment of alfalfa interseeded into rangeland in South Dakota. After interseedings become established, grasshoppers continue to be the most damaging insect to alfalfa in semiarid rangelands (Hewitt 1977). Grasshoppers asso-

\footnotetext{
Authors are research geneticist, USDA-ARS, Northern Great Plains Research Laboratory, Mandan, North Dakota 58554; research entomologist (retired), USDAARS, Rangeland Insect Laboratory, Montana State University, Bozeman, Montana 57717; and research entomologist, ICARDA, P.O. Box 5466, Aleppo, Syria, respectively.

Contribution of the Agricultural Research Service, USDA.

Technical assistance of R.A. Wald and C.J. Foiles is gratefully acknowledged.

Manuscript accepted 29 November 1989.
}

ciated with alfalfa in the northern Great Plains are primarily Melanoplus spp. that have a wide range of hosts plants but prefer forbs (Brooks 1958, Mulkern et al. 1964, Joern 1983).

Insecticide application often is not economical for rangelands, and grasshopper control from insecticides is of short duration. Lockwood et al. (1988) pointed out that use of broad-spectrum insecticides may have counterproductive effects on long-term suppression of grasshopper populations through large-scale destruction of natural parasites and predators of the grasshopper. Alfalfa germplasm with low preference to several Melanoplus spp. would be valuable for interseeding into rangelands of the northern Great Plains where grasshoppers are a potential problem.

Harvey and Hackerott (1976) reported differences in defoliation among alfalfa plants from the cultivar 'Buffalo' that were subjected to feeding from a grasshopper population composed of Encoptolophus sordidus costalis (Scudder), Schistocerca lineata (Scudder), Melanoplus differentialis (Thomas), and M. femurrubrum (DeGeer). More recently, Hewitt and Berdahl (1984) reported similar ranking in grasshopper preference among alfalfa cultivars in laboratory tests involving the grasshopper species Melanoplus packardii (Scudder) and $M$. sanguinipes (F.) and in field tests involving 5 naturally occurring Melanoplus spp. Consistent differences in defoliation among alfalfa cultivars in a field environment from a natural population of species that prefer forbs prompted us to initiate recurrent phenotypic selection for low grasshopper preference in an alfalfa population adapted to semiarid rangeland.

This study reports heritability estimates of grasshopper preference in alfalfa and evaluates progress from 5 cycles of recurrent phenotypic selection for low preference.

\section{Materials and Methods}

\section{Recurrent Selection}

Recurrent phenotypic selection procedures used in this study are presented in Table 1 . The cycle 1 population for recurrent phenotypic selection was derived from 125 plants that had been selected for low grasshopper defoliation from 5 cultivars ('Spredor 2', 'Travois', 'Teton', 'Rangelander', and 'Drylander') and an experimental strain, Mandan A2811. These cultivars and Mandan A2811 had medium to low grasshopper preference relative to other alfalfa cultivars in a previous field evaluation (Hewitt and Berdahl 1984). All are winterhardy and have broad, deep-set crowns, and all except Teton have varying degrees of proliferation from creeping roots. The 125 parent plants were clonally replicated 4 times and intercrossed in a greenhouse under a cage using leafcutter bees [Megachile rotundata (Fabr.)]

The number of parent selections used to produce the cycle 1 population of half-sib families was $44,23,18,17,14$, and 9 , respectively, from Spredor 2, Travois, Mandan A2811, Rangelander, Teton, and Drylander. Individual plants of the cycle 1 population were grown in cone-shaped plastic containers $(4.0-\mathrm{cm}$ diam top tapering over a $22-\mathrm{cm}$ depth to a $2.5-\mathrm{cm}$ diam bottom) for 6 weeks in a greenhouse and hardened outdoors for 2 weeks. Then they were transferred in racks to a field infested with a population of adult grasshoppers to determine preference in an environment 
Table 1. Procedures for 5 cycles of recurrent phenotypic selection in alfalfa for low grasshopper food preference.

\begin{tabular}{|c|c|c|c|}
\hline Year & Environment & $\begin{array}{l}\text { Selection } \\
\text { cycle }\end{array}$ & Population and selection intensity \\
\hline \multirow[t]{2}{*}{1982} & Field & 0 & $\begin{array}{l}125 \text { plants selected from } 5 \\
\text { cultivars and } 1 \text { experi- } \\
\text { mental strain }\end{array}$ \\
\hline & & & intermate \\
\hline \multirow[t]{2}{*}{1983} & Field & 1 & $\begin{array}{l}125 \text { half-sib families, 3-plant plots, } \\
4 \text { replicates }\end{array}$ \\
\hline & & & $\begin{array}{l}\text { intermate } 49 \text { selections } \\
\text { from } 43 \text { cycle-1 families }\end{array}$ \\
\hline \multirow[t]{2}{*}{1984} & Field & 2 & $\begin{array}{l}49 \text { half-sib families, } 8 \text {-plant } \\
\text { plots, } 4 \text { replicates }\end{array}$ \\
\hline & & & $\begin{array}{l}\text { intermate } 49 \text { selections from } \\
20 \text { cycle- } 2 \text { families }\end{array}$ \\
\hline \multirow[t]{2}{*}{1985} & Field & 3 & $\begin{array}{l}49 \text { half-sib famlies, 8-plant plots, } \\
4 \text { replicates }\end{array}$ \\
\hline & & & $\begin{array}{l}\text { intermate } 49 \text { selections } \\
\text { from } 19 \text { cycle-3 families }\end{array}$ \\
\hline \multirow[t]{2}{*}{1986} & Greenhouse & 4 & $\begin{array}{l}49 \text { half-sib families, 8-plant plots } \\
4 \text { replicates (Defoliated under } \\
\text { a cage with sweep-net samples } \\
\text { of grasshoppers) }\end{array}$ \\
\hline & & & $\begin{array}{l}\text { intermate } 64 \text { selections from } \\
26 \text { cycle }-4 \text { families }\end{array}$ \\
\hline \multirow[t]{2}{*}{1987} & Field & 5 & $\begin{array}{l}64 \text { half-sib families, 8-plant } \\
\text { plots, } 4 \text { replicates }\end{array}$ \\
\hline & & & $\begin{array}{l}\text { intermate } 64 \text { selections from } \\
28 \text { cycle- } 5 \text { families }\end{array}$ \\
\hline
\end{tabular}

that simulated natural rangeland conditions. Three plants of each half-sib family were included in each of 4 replicates in a randomized complete block design for a total of 1,500 plants. No spacing was present between the contiguous plots. Defoliation was scored on a scale from $1-5$ where $1=0-20 \%$ defoliation, $2=21-40 \%, 3=$ $41-60 \%, 4=61-80 \%$, and $5=81-100 \%$. Three trained evaluators scored individual plants within each plot when the entire population of plants was at least $50 \%$ defoliated. An average defoliation score was recorded for each plot.

A total of 49 individual plant selections from $\mathbf{4 3}$ families was made from the cycle 1 population. Selection was based on defoliation scores of families averaged over 4 replicates. For the first selection cycle, a constraint was placed on selection so that plants selected to produce the cycle 2 population traced to all 5 parent cultivars and Mandan A2811 in approximately the same proportion as they were represented in cycle 1 . After intermating to produce the cycle 2 population, selection in subsequent cycles was based only on mean defoliation scores of replicated half-sib families, with no regard for pedigree.

Experimental error for defoliation scores was high in the cycle 1 evaluation ( $\mathrm{CV}=24 \%$ ), and several procedures were changed for subsequent selection cycles. Plant height of the contiguous plots in cycle 1 averaged $20 \mathrm{~cm}$ when defoliation was scored, and branches of plants in adjacent plots had become intertwined. Plot size was increased from 3 to 8 plants to form a larger, square-shaped plot with a vacant space in the center, and plots were symmetrically arranged in racks with a $17-\mathrm{cm}$ lineal and $8-\mathrm{cm}$ diagonal spacing between all plots. This plot size and spacing improved grasshopper discrimination among families compared to the contiguous plots in cycle 1 . A partially balanced lattice design with 4 replicates was used to reduce experimental error caused by non-uniform grasshopper densities within replicates. In addition, a Spredor 2 check plot (low preference) was included at 10-plot intervals to provide a base-line for comparing progress among selection cycles.

The number of half-sib families per cycle of selection was reduced from 125 in cycle 1 to 64 or 49 for the subsequent 4 cycles. Selection intensity among families varied from 39 to $53 \%$ for subsequent cycles. Further selection was practiced within selected half-sib families for low defoliation of individual plants at a selection intensity of 3 to $9 \%$ ( 1 to 3 plants per family). Selection continued to be practiced on 6-to 8-week-old plants in subsequent cycles. Low grasshopper densities in the field in 1986 required an evaluation of the cycle 4 population under a cage in a greenhouse using a grasshopper population obtained from sweep-net samples (Table 1). After defoliation scores were recorded in 1983 and 1987 for cycle 1 and cycle 5 , respectively, the alfalfa populations were subjected to additional grasshopper feeding in the field to determine if any half-sib families had high levels of resistance.

\section{Heritability Estimates}

Estimates of narrow-sense heritability were based on parental means of 2 clonally replicated plots per entry, each plot consisting of 3 propagules, and half-sib family means of 4 replicates of 8-plant plots. Plots of the 31 parents (10-week-old cuttings of plants selected from cycle 2 ) and their respective half-sib families (8-weekold plants) were evaluated for grasshopper defoliation in separate years in cages in a greenhouse. Parents and half-sib families were hardened outdoors for 2 weeks prior to grasshopper feeding. Parents and half-sib families were rated for defoliation by 3 evaluators on a scale from $1-5$ where $1=0-20 \%$ and $5=81-100 \%$ defoliation. Defoliation percentage of the clonally propagated parent plots also was estimated by subtracting the dry weight of plots after feeding from the dry weight of a control treatment of clonally propagated plots that were excluded from feeding. Half-sib family means were regressed on maternal parent means for 31 entries, and the linear regression coefficient was multiplied by a coefficient of 2 to provide an estimate of narrow-sense heritability, the ratio of additive genetic variance to phenotypic variance for the parents (Falconer 1983). When defoliation of parents was expressed as a percentage, defoliation scores ( 1 to 5) of progeny were multiplied by 20 to convert score ratings to percentages. All parent and progeny data were normally distributed.

\section{Simultaneous Evaluation of Selection Cycles}

Alfalfa populations produced by intermating plant selections made in cycles 1,3 , and 5 were evaluated simultaneously in 1988 for grasshopper defoliation. Plants were grown in a greenhouse for 6 weeks and then hardened outdoors for 2 weeks before being exposed to a caged grasshopper population under greenhouse conditions. The experimental unit for each of the 3 alfalfa populations was a 28-plant plot in 20 replicates in a randomized complete block design. Melanoplus femurrubrum comprised $54 \%$ of the grasshopper population, $M$. sanguinepes $18 \%$, and 6 other forbfeeding Melanoplus spp. and Camnula pellucida (Scudder) made up $17 \%$ of the population. Six grass-feeding species comprised the remaining $11 \%$ of the population. Defoliation was scored, as previously described, on a scale from 1 to 5 by 3 evaluators on individual plants and averaged for each plot.

\section{Results and Discussion}

\section{Evaluation of Selection Progress}

A discrepancy was found between selection progress indicated by annual comparisons of each selection cycle relative to a Spredor 2 check (Table 2) and progress indicated by a more critical simultaneous comparison of selection cycles 1,3 , and 5 (Table 3). Species composition of the grasshopper population changed from cycle to cycle in the annual comparisons (Table 4), while a common population comprised of important forb-feeding species was used for the simultaneous comparison. In the annual comparisons, the 
Table 2. Minimum, maximum, and mean defollation scores of half-sib families for 5 cycles of recurrent phenotypic selection for low grasshopper food preference in alfalin and the relationship of family means to a low-preference Spredor 2 check.

\begin{tabular}{|c|c|c|c|c|c|}
\hline \multirow[b]{2}{*}{ Cycle } & \multicolumn{3}{|c|}{$\begin{array}{l}\text { Defoliation score }(1-5)^{1} \text { of half-sib } \\
\text { families in selected population }\end{array}$} & \multirow{2}{*}{$\begin{array}{l}\text { Spredor } 2 \\
\text { Score }(1-5)^{1} \\
\end{array}$} & \multirow{2}{*}{$\begin{array}{l}\% \text { families } \\
<\text { Spredor } 2\end{array}$} \\
\hline & Minimum & Maximum & Mean \pm SE & & \\
\hline 0 & - & - & 3.6 & 3.2 & - \\
\hline 1 & 1.8 & 4.8 & $3.1 \pm 0.4$ & - & - \\
\hline 2 & 2.5 & 4.6 & $3.6 \pm 0.4$ & 3.1 & 12 \\
\hline 3 & 2.2 & 4.3 & $3.1 \pm 0.4$ & 2.7 & 24 \\
\hline 4 & 1.6 & 4.7 & $3.5 \pm 0.3$ & 3.3 & 39 \\
\hline 5 & 2.1 & 4.5 & $3.3 \pm 0.3$ & 3.6 & 61 \\
\hline
\end{tabular}

$11=1-20 \%$ defoliation, $5=81-100 \%$ defoliation.

percentage of half-sib families with less defoliation than the overall mean of the Spredor 2 check increased successively from $12 \%$ in cycle 2 to $61 \%$ in cycle 5 (Table 2). Mean defoliation scores of families in cycle 5 ranged from 2.1 to 4.5 , indicating that a large amount of phenotypic variance for grasshopper preference was still present in the selected population and that additional gain from selection would likely be possible. When populations produced from cycles 1,3 , and 5 were evaluated simultaneously, defoliation decreased significantly from cycle 1 to cycle 3 , but no significant progress was made from cycle 3 to cycle 5 (Table 3 ). Differences in preference for alfalfa genotypes among grasshopper species is a plausible explanation for this lack of agreement between the 2 methods for evaluating selection progress.

Table 3. Response of an alfalia population to recurrent phenotypic selection for low grasshopper food preference as indicated by the frequency distribution of plants in 5 defoliation score categories and the mean score of populations produced from selection cycles, 1,3 , and 5 .

\begin{tabular}{|c|c|c|c|c|c|c|c|}
\hline \multirow{2}{*}{$\begin{array}{l}\text { Selection } \\
\text { cycle }^{1}\end{array}$} & \multicolumn{5}{|c|}{ Defoliation score 2} & \multirow{2}{*}{$\begin{array}{c}\text { Total } \\
\text { no. plants }\end{array}$} & \multirow{2}{*}{$\begin{array}{l}\text { Mean } \\
\text { score }\end{array}$} \\
\hline & 1 & 2 & 3 & 4 & 5 & & \\
\hline & - & $\cdots$ & $\%$ & $-\cdots$ & -- & & \\
\hline 1 & 6 & 14 & 24 & 39 & 17 & 560 & 3.83 \\
\hline 3 & 14 & 25 & 30 & 24 & 7 & 560 & 3.25 \\
\hline 5 & 17 & 27 & 29 & 22 & 6 & 560 & 3.15 \\
\hline LSD. .06 & & & & & & & 0.23 \\
\hline
\end{tabular}

'Selection cycles 1,3 , and 5 evaluated simultaneously under greenhouse conditions. 2Score categories $1-5$ where $1=0-20 \%$ defoliation and $5=81-100 \%$ defoliation.

Results from a previous study (Hewitt and Berdahl 1984) also suggest that different forb-feeding grasshopper species have distinct preferences for different alfalfa genotypes. Inconsistencies occurred in their study between laboratory and field tests for grasshopper preference among alfalfa cultivars, even though overall ranking of cultivars was similar. First, relative differences in grasshopper preference among cultivars was much greater in the laboratory than in the field tests. Secondly, two notable changes in rank occurred among 8 cultivars tested in the laboratory and field. 'Rangelander' had high preference in laboratory tests and relatively low preference in the field test, while the opposite response was found for 'Ladak 65', which had low preference in the laboratory and relatively high preference in the field. The grasshopper species in their study differed among the laboratory and field tests. Laboratory tests evaluated alfalfa defoliation and consumption using either $M$. packardii or $M$. sanguinipes, and the field test primarily involved $M$. femurrubrum and $M$. differentialis.

Grasshopper species in this study differed markedly among the different selection cycles (Table 4), even though $M$. femurrubrum was always the dominant species. Mulkern et al. (1962) also reported a high percentage of $M$. femurrubrum in grasshopper populations associated with alfalfa across North Dakota over several years. The second-ranked species changed drastically after cycle 3 with the replacement of $M$. differentiallis by $M$. sanguinipes. Other species are listed in Table 4; all of the Melanoplus spp.

\section{Table 4. Species composition of grasshopper populations sampled at fleld} screening sites near Mandan, ND.

Species composition ( $\%$ of population) for individual selection cycles ${ }^{1}$

Grasshopper species Cycle 0 Cycle 1 Cycle 2 Cycle 3 Cycle 4 Cycle 5

\begin{tabular}{lrrrrrr}
\hline Melanoplus & & & & & & \\
$\quad$ bivittatus & 3 & 4 & 12 & 14 & 3 & 2 \\
$M$. differentialis & 23 & 15 & 28 & 45 & $<1$ & 1 \\
$M$. femurrubrum & 67 & 72 & 31 & 40 & 59 & 79 \\
$M$. packardii & 3 & 6 & 6 & $<1$ & 1 & 1 \\
M. sanguinipes & 3 & 1 & 12 & $<1$ & 16 & 11 \\
Aeneotettix deorum & 0 & 0 & 3 & 0 & 0 & \\
Camnula pellucida & $<1$ & 0 & 3 & $<1$ & 1 & $<1$ \\
$\begin{array}{l}\text { Phoetaliotes } \\
\quad \text { nebrascensis }\end{array}$ & $<1$ & 2 & 4 & 0 & 3 & 1 \\
Trachyrachys kiowa & 0 & 0 & 1 & 0 & 2 & 0 \\
\hline
\end{tabular}

IAll other Acrididae species constituted $<5 \%$ of the total population in any given selection cycle.

are known to prefer forbs (Mulkern et al. 1964, Joern 1983), and differences in food preference for alfalfa genotypes likely exist among the grasshopper species.

Species composition of grasshopper populations also will vary with years and location in rangeland environments. If selection is to be effective, low preference for alfalfa must be a generalized reaction that applies to some degree to several grasshopper species. Little or no gain for low preference was quantified between cycle 3 and cycle 5 of recurrent phenotypic selection (Table 3) when a major change occurred in species compusition of the grasshopper populations used in the selection process (Table 4). While these results are superficially discouraging, it should be noted that previous gains were maintained despite the shift in species composition. The cycle 5 population had lower preference scores than Spredor 2 (Table 2), the least preferred cultivar in all field and laboratory tests. When cycles were evaluated simultaneously, plants in score categories 1 and $2(<40 \%$ defoliation) increased from $20 \%$ of the selected population after cycle 1 to $44 \%$ after cycle 5 (Table 3). Percentage of plants in score categories 4 and $5(>60 \%$ defoliation) was $56 \%$ after cycle 1 and $28 \%$ after cycle 5 . Selection progress, although not as rapid as anticipated from preliminary heritability estimates, was still achieved as evidenced by an overall reduction in preference for an alfalfa population by a reference population of grasshoppers.

\section{Heritability Estimates}

Defoliation scores varied from 1.33 to 3.75 among 31 parental clones and from 1.96 to 4.77 among respective half-sib progenies used for heritability estimates. Defoliation measured from the difference in dry weights between grasshopper exposed plots and control plots of the parental clones varied from 18 to $61 \%$. Dry weights provided a more accurate estimate of defoliation than a visual score, because defoliation scores for small plants were biased upwards. The correlation coefficient was 0.89 between mean visual defoliation scores and mean defoliation percentages based on dry weights averaged over 2 replicates for the 31 parents used in heritability estimates. Narrow-sense heritability estimates were 45 $\pm 31 \%$ when progeny scores were regressed on parent scores and 58 
$\pm 41 \%$ when progeny scores were converted to defoliation percentages and regressed on defoliation percentages of parents measured from plant dry weights. Thus, heritability from replicated visual defoliation scores was high enough to allow gain from selection. Use of visual defoliation scores was more efficient, considering the resources that were required to obtain reliable dry weights of defoliated and control plots. Predominant grasshopper species for evaluation of both parents and progenies were $M$. femurrubrum and $M$. differentialis. Heritability estimates of defoliation apply to the grasshopper populations and other factors common to this study.

\section{Considerations in Selection for Low Preference}

In selecting for low grasshopper preference, screening tests must include concurrent use of several forb-feeding grasshopper species. If a predominant grasshopper species occurs, such as $M$. femurrubrum in the northern Great Plains, this species should be a major component of the grasshopper population used in screening. Uneven distribution and feeding of grasshoppers within individual replicates was a major source of experimental error in this study. A lattice design was effective in reducing this source of error as evidenced by relative efficiencies of 111 to $170 \%$ for a partially balanced lattice compared with a randomized complete block design. In all instances, relative differences in defoliation scores among entries were consistent for all 3 evaluators as evidenced by nonsignificant entry by evaluator interactions. Thus, all defoliation scores reported reflect an average of the 3 evaluators.

It would be helpful to know specific plant traits that confer low grasshopper preference to alfalfa. Eight-week-old seedlings of 'Roamer', a cultivar with high preference, averaged $1 \%$ higher crude fiber than Spredor 2, a cultivar with low preference (data not presented). Percentage protein, ether extract, and ash were not significantly different for the 2 cultivars (data not presented). Thus, in a comparison of 2 cultivars, forb-feeding grasshoppers did not discriminate against the cultivar with significantly higher fiber content. Bernays and Chapman (1978) reported that secondary plant compounds influence host-plant selection by various insects through either deterrence or stimulation. Identification of a chemical basis for low grasshopper preference for alfalfa might offer the possibility of using a simple chemical assay as a selection criterion. Simple morphological traits such as decumbent growth habit also may reduce grasshopper feeding (Harvey and Hackerott 1976).

\section{Conclusions}

Five cycles of recurrent phenotypic selection in alfalfa for low grasshopper preference reduced defoliation by a grasshopper population consisting of several common forb-feeding species. Reduc- tion in defoliation was due to a reduction in preference; eventually, selected alfalfa populations were completely defoliated by high densities of forb-feeding grasshopper. Although forb-feeding grasshoppers have a wide range of host plants, data from this study suggested that individual Melanoplus sp. have distinct preferences for alfalfa genotypes. Levels of low grasshopper preference for the cycle 5 alfalfa population have not been measured over a series of rangeland environments that would provide a representative sample of different grasshopper species, ages, and population densities.

\section{Literature Cited}

Bernays, E.A., and R.F. Chapman. 1978. Plant chemistry and acridoid feeding behaviour. p. 99-141. In: H.B. Harborne (ed.). Biochemical Aspects of Plant and Animal Coevolution: Annu. Proc. Phytochem. Soc. Europe. No. 15. Academic Press, New York.

Brooks, A.R. 1958. Acridoidea of southern Alberta, Saskatchewan, and Manitoba (Orthoptera). Canadian Entomol. Suppl. 9. 92 p.

Campbell, J.B. 1963. Grass-alfalfa versus grass-alone pastures grazed in a repeated-season pattern. J. Range Manage. 16:78-81.

Falconer, D.S. 1983. Introduction to quantitative genetics. 2nd ed. The Ronald Press Co., New York.

Gomm, F.B. 1964. A comparison of two sweetcover strains and Ladak alfalfa alone and in mixtures with crested wheatgrass for range and dryland seeding. J. Range Manage. 17:19-23.

Harvey, T.L., and H.L. Hackerott. 1976. Grasshopper-resistant alfalfa selected in the field. Environ. Entomol. 5:572-574.

Heinrichs, D.H., T. Lawrence, and J.D. McElgunn. 1979. Rangelander alfalfa. Can. J. Plant Sci. 59:491-492.

Hewitt, G.B. 1977. Review of forage losses caused by rangeland grasshoppers. USDA-ARS Misc. Pub. 13. 24 p.

Hewitt, G.B., and J.D. Berdahl. 1984. Grasshopper food preferences among alfalfa cultivars and experimental strains adapted for rangeland interseeding. Environ. Entomol. 13:828-831.

Joern, A. 1983. Host plant utilization by grasshoppers (Orthoptera: acrididae) from a sandhills prairie. J. Range Manage. 36:793-797.

Lockwood, J.A., W.P. Kemp, and J.A. Onsager. 1988. Long-term, largescale effects of insecticidal control on rangeland grasshopper populations (Orthoptera: Acrididae). J. Econ. Entomol. 81:1258-1264.

Lorenz, R.J., and G.A. Rogler. 1962. A comparison of methods of renovating old stands of crested wheatgrass. J. Range Manage. 15:215-219.

Mulkern, G.B., D.R. Toczek, and M.A. Brusven. 1964. Biology and ecology of North Dakota grasshoppers. II. Food habits and preference of grasshoppers associated with the Sand Hills Prairie. ND Agr. Exp. Sta. Res. Rep. 11.59 p.

Mulkern, G.B., J.F. Anderson, and M.A. Brusven. 1962. Biology and ecology of North Dakota grasshoppers. I. Food habits and preferences of grasshoppers associated with alfalfa fields. ND Agr. Exp. Sta. Res. Rep. 7. 26 p.

Rumbaugh, M.D., J.D. Colburn, and G. Semeniuk. 1964. Registration of Travois alfalfa. Crop Sci. 4:117.

Rumbaugh, M.D., and T. Thom. 1965. Initial stands of interseeded alfalfa. J. Range Manage. 18:258-261. 